Research Paper

\title{
FOXO1 Is Involved in the Effects of Cigarette Smoke Extract on Osteoblastic Differentiation of Cultured Human Periosteum-derived Cells
}

\author{
Iel-Yong Sung, ${ }^{1}$ Bong-Chan Park, ${ }^{1}$ Young-Sool Hah, ${ }^{2}$ Hee-Young Cho, ${ }^{2}$ Jeong-Won Yun, ${ }^{2}$ Bong-Wook Park, ${ }^{3}$ \\ Young-Hoon Kang, ${ }^{3}$ Ho-Cheol Kim, ${ }^{4}$ Sun-Chul Hwang, ${ }^{5}$ Gyu-Jin Rho, 6 Uk-Kyu Kim,, ${ }^{7}$ Dong Kyun Woo, ${ }^{8}$ \\ Se-Heang Oh, ${ }^{9}$ June-Ho Byun ${ }^{3}$ \\ 1. Department of Oral and Maxillofacial Surgery, College of Medicine, Ulsan University, Ulsan, Republic of Korea \\ 2. Clinical Research Institute of Gyeongsang National University Hospital, Jinju, Republic of Korea \\ 3. Department of Oral and Maxillofacial Surgery, Gyeongsang National University School of Medicine and Gyeongsang National University Hospital, Insti- \\ tute of Health Sciences, Gyeongsang National University, Jinju, Republic of Korea \\ 4. Department of Internal Medicine, Institute of Health Sciences, Gyeongsang National University School of Medicine, Jinju, Republic of Korea \\ 5. Department of Orthopaedic Surgery, Institute of Health Sciences, Gyeongsang National University School of Medicine, Jinju, Republic of Korea \\ 6. OBS/Theriogenology and Biotechnology, College of Veterinary Medicine, Gyeongsang National University, Jinju, Republic of Korea \\ 7. Department of Oral and Maxillofacial Surgery, School of Dentistry, Pusan National University, Yangsan, South Korea \\ 8. College of Pharmacy and Research Institute of Pharmaceutical Sciences, Gyeongsang National University, Jinju, Republic of Korea \\ 9. Department of Nanobiomedical Science, Dankook university, Cheonan, Republic of Korea
}

$\square$ Corresponding author: June-Ho Byun, Department of Oral and Maxillofacial Surgery, Institute of Health Sciences, Gyeongsang National University School of Medicine, Jinju, 660-702, Republic of Korea. E-mail: surbyun@gsnu.ac.kr

(c) 2015 Ivyspring International Publisher. Reproduction is permitted for personal, noncommercial use, provided that the article is in whole, unmodified, and properly cited. See http://ivyspring.com/terms for terms and conditions.

Received: 2015.07.07; Accepted: 2015.09.20; Published: 2015.10.21

\begin{abstract}
Cigarette smoke is associated with delayed fracture healing, alterations in mineral content, and osteoporosis, however, its effects on osteoblastic differentiation of osteoprogenitor cells are not fully understood. In the present study, we examined the effects of cigarette smoke extract (CSE) on osteoblastic differentiation of cultured human periosteum-derived cells. We found that CSE inhibited alkaline phosphatase (ALP) activity, mineralization and Runx2 transactivation of the periosteum-derived cells. Nucleofection of RUNX2 into the periosteum-derived cells increased expression of endogenous osteocalcin (OC) and ALP genes in osteogenic induction medium and increased $O C$ expression in non-osteogenic medium. Treatment of the periosteum-derived cells with CSE resulted in decreased phosphorylation of AKT and forkhead box protein OI (FOXOI). The AKT phosphorylation-resistant mutant, FOXO1-A3, inhibited transcriptional activity of RUNX2 in the periosteum-derived cells. The current study suggests one mechanism by which CSE exposure leads to inhibition of osteoblastic differentiation of cultured human periosteum-derived cells.
\end{abstract}

Key words: Periosteum-derived cells, Osteoblastic differentiation, RUNX2 activity, FOXO1

\section{Introduction}

Cigarette smoke consists of more than 6,000 compounds, of which more than 150 are known toxic compounds that contribute to the pathogenesis of a variety of diseases. Although the mechanisms by which cigarette smoke cause disease remain to be fully determined, some data suggest that toxins contained in cigarette smoke may not only initiate and exacerbate tissue injury but may also impair repara- tive processes via the initiation of inflammatory responses. Cigarette smoke has negative effects on bone-forming cells and skeletal bone in animal and human models and is associated with delayed fracture repair and increased nonunion rates. In dental clinics, smoking is one of the most common risk factors for post-extraction complications [1-7]. Bone is a physiologically dynamic tissue with considerable 
self-regenerative capacity. One of the most important factors associated with the self-healing capacity of bone is its high level of vascularization. Smoking decreases the filling of post-extraction sockets with blood and exerts an adverse effect on bone healing of the extraction wound. When impacted teeth are surgically extracted, smoking may not only increase the possibility of alveolar osteitis, but also influence the adjacent periosteum, which functions as one source of the stem cells involved in infilling of the extraction socket with bone [8,9].

The periosteum contains multipotent cells that have characteristics similar to those of bone marrow-derived mesenchymal stem cells and are able to differentiate into osteoblasts and chondrocytes. A significant advantage of using periosteum-derived cells for bone tissue engineering in the clinical setting, such as for surgical extraction of an impacted third molar tooth, is the relative ease of harvesting donor tissue. In our previous study, we demonstrated that periosteum-derived cells differentiate into active osteoblastic cells that are involved in the mineralization of the matrix $[10,11]$.

RUNX2 is a key transcriptional regulator of osteoblast differentiation. The binding of nuclear RUNX2 to osteoblast-specific elements up-regulates skeletal genes and consequently promotes development of the osteoblast phenotype. Many of the signaling pathways and transcriptional factors that influence osteoblastogenesis do so by influencing the production or activity of RUNX2. In addition, expression of exogenous RUNX2 in nonosteoblastic cells induces expression of the principal osteoblast-specific genes [12-14]. Forkhead box O1 (FOXO1) belongs to the family of transcription factors that is characterized by a 100-amino acid monomeric DNA-binding domain called the FOX domain. FOXO proteins comprise a subgroup of the FOX family and play important roles in regulating expression of genes in a variety of physiological processes, specifically in many cancer-related functions. FOXO1 not only plays a role as a tumor suppressor, but also induces expression of target genes involved in apoptosis, glucose metabolism, cell cycle progression, and differentiation, and is central to the decision of a preadipocyte to commit to adipogenesis. FOXO1 is primarily regulated through phosphorylation of multiple residues, i.e., Thr24, Ser253, and Ser316. The transcriptional activity of FOXO1 is dependent on its phosphorylation state. As a member of the forkhead-O family of transcription factors, FOXO1 is also a potentially important transcription factor in regulating formation of a mineralizing matrix [15-18].

To our knowledge, there is limited evidence regarding the effects of cigarette smoke extract (CSE) on osteoblastic differentiation of cultured human periosteum-derived cells. The purpose of this study was to examine the effects of CSE on osteogenic phenotypes of cultured human periosteum-derived cells. In addition, the role of FOXO1 in RUNX2 activity of the periosteal-derived cells treated with CSE was also examined.

\section{Materials and methods}

\section{Preparation of CSE}

Filter cigarettes, each containing $0.1 \mathrm{mg}$ nicotine and $1 \mathrm{mg}$ tar, were used to prepare the smoke extract. CSE was prepared in a fume hood by bubbling the smoke from a cigarette in a holder attached by rubber tubing to a peristaltic pump. The pump outflow track was attached by rubber tubing to a glass straw submerged in phosphate-buffered saline (PBS). Smoke from ten cigarettes was passed through $20 \mathrm{ml}$ PBS to obtain $100 \%$ CSE. Final concentrations of $0.5 \%, 1 \%$, $2 \%$, and $3 \%$ were used in the proliferation assay; final concentrations of $0.01 \%, 0.05 \%, 0.1 \%$, and $0.5 \%$ CSE were used for all other experiments. Control extracts were similarly prepared from unlit cigarettes. Extracts were separated into aliquots and stored at $-20^{\circ} \mathrm{C}$.

\section{Cell Proliferation Assay}

Proliferation of the periosteum-derived cells was assayed using the Cell Counting Kit (CCK)-8 (Dojindo, USA). Briefly, $3 \times 10^{5}$ cells were seeded onto a 96-well plate and cultured for 24 hours in Dulbecco's modified Eagle medium (DMEM) containing 0\% to $3 \%$ CSE. After incubation, the cells were treated with $10 \mu \mathrm{l} \mathrm{CCK-8} \mathrm{solution/well} \mathrm{and} \mathrm{incubated} \mathrm{for} 1 \mathrm{~h}$ at $37^{\circ} \mathrm{C}$. Formazan dye generation by cellular dehydrogenase activity was then determined by measuring absorbance at $450 \mathrm{~nm}$ using a microplate reader. Cell viability was expressed as percent viability of control cells cultured in the absence of CSE.

\section{Osteoblastic Differentiation and CSE Treat- ment of Periosteum-derived cells}

Patients provided informed consent for collection of periosteal tissues, as required by the Ethics Committee of Gyeongsang National University Hospital (GNUH 2014-05-012). Periosteum-derived cells were cultured using a previously described technique $[10,11]$. Pieces of periosteal tissue were placed in a $100-\mathrm{mm}$ culture dish and cultured in DMEM supplemented with $10 \%$ fetal bovine serum (FBS), 100 $\mathrm{IU} / \mathrm{ml}$ penicillin, and $100 \mu \mathrm{g} / \mathrm{ml}$ streptomycin at $37^{\circ} \mathrm{C}$ in a humidified atmosphere of $95 \%$ air and $5 \% \mathrm{CO}_{2}$. Osteoblastic differentiation was induced by culture of passage-three periosteal cells seeded at a density of 3 $\times 10^{4}$ cells/well in 24-well plates in osteogenic induction medium $(\mathrm{OM})$ composed of DMEM supple- 
mented with $10 \%$ FBS, $50 \mu \mathrm{g} / \mathrm{ml}$ L-ascorbic acid 2-phosphate, $10 \mathrm{nM}$ dexamethasone, and $10 \mathrm{mM}$ $\beta$-glycerophosphate. Medium was changed every 3 days during osteoblastic differentiation. Cells cultured in $\mathrm{OM}$ were treated with $0 \%$ (control) to $0.5 \%$ CSE.

\section{Histochemical Detection of Alkaline Phos- phatase (ALP) Activity in Periosteum-derived cells}

ALP is an early marker of osteoblast differentiation [10]. Histochemical detection and measurement of ALP activity were carried out after culturing cells for 1 and 2 weeks. Briefly, cells were stained with fast 5-bromo-4-chloro-3-indolyl phosphate and nitroblue tetrazolium (BCIP/NBT) ALP substrate (Amresco, USA). ALP activity was determined using $50 \mathrm{mmol} / 1$ p-nitrophenylphosphate in a glycine- $\mathrm{NaOH}$ buffer at $\mathrm{pH}$ 10.4. The amount of p-nitrophenylphosphate released was estimated by measuring the absorbance at $410 \mathrm{~nm}$.

\section{Alizarin Red S Staining of Mineralized Tissue and Quantification of Calcium in Perioste- um-derived cells}

Secretion of osteocalcin (OC) and matrix mineralization are associated with the final phase of osteoblast differentiation [10]. Alizarin red S staining and determination of calcium content were performed after culturing cells for 2 weeks as previously described $[10,11]$. Briefly, cells were stained with $2 \%$ alizarin red S. To quantify the intensity of staining, cultures were incubated with $100 \mathrm{mM}$ cetylpyridinium chloride (Sigma-Aldrich, USA) for 2 hours to release the calcium-bound dye. Calcium content was determined by spectrophotometry using the o-cresolphthalein method (Calcium C-test Wako; Wako Pure Chemical Industries, Japan).

\section{Quantitative reverse Transcrip- tion-polymerase Chain Reaction (RT-PCR) Analysis}

Total RNA was extracted from differentiating periosteum-derived cells using TRIzol ${ }^{\circledR}$ Reagent (Life Technologies, USA), and cDNAs were generated using random hexamer primers provided in the Applied Biosystems ${ }^{\circledR}$ first-strand cDNA synthesis kit (Life Technologies, USA). Quantitative real-time PCR was performed using primers specific for human ALP and OC. GAPDH served as an internal control. All primers and probes (ALP, Cat \#Hs01029144-m1; OC, Cat \#Hs00609452-g1; GAPDH, Cat \#Hs02758991-g1) were obtained commercially as part of Applied Biosystems ${ }^{\circledR}$ TaqMan ${ }^{\circledR}$ Gene Expression Assays (Life Technologies, USA) and amplified using Applied Bi- osystems ${ }^{\circledR}$ TaqMan ${ }^{\circledR}$ Gene Expression Master Mix according to the manufacturer's instructions. Amplification was carried out under conditions of $50^{\circ} \mathrm{C}$ for 2 $\min , 95^{\circ} \mathrm{C}$ for $10 \mathrm{~min}$, and 40 cycles of $94^{\circ} \mathrm{C}$ for $15 \mathrm{~s}$ and $60^{\circ} \mathrm{C}$ for $1 \mathrm{~min}$, in 96-well plates using the Applied Biosystems ${ }^{\circledR}$ ViiA $^{\mathrm{TM}} 7$ Real-Time PCR System (Life Technologies, USA). All experiments were performed in triplicate.

\section{Plasmids, Nucleofection and Luciferase Assay}

To examine the functional role of CSE on RUNX2 activity in the periosteum-derived cells, the effect of overexpression of RUNX2 was evaluated in confluent monolayers of periosteum-derived cells transiently co-transfected with a p6xOSE2-Luc reporter and RUNX2 expression vector using a previously described technique [19]. Vectors for expression of wild-type FOXO1 (FOXO1-WT) and constitutively active FOXO1 (FOXO1-A3) (plasmids 13507 and 13508, respectively) were obtained from Addgene (USA). Cells were nucleofected using the P2 Primary Cell 4D-Nucleofector ${ }^{\mathrm{TM}} \mathrm{X}$ Kit (Lonza, USA) according to the manufacturers' recommendations. Briefly, $5 \times$ $10^{5}$ cells were resuspended in $100 \mu \mathrm{l}$ Nucleofector solution, mixed with the p6 $\times$ OSE2-Luc reporter plasmid and combinations of RUNX2 and FOXO1 expression constructs ( $0.6 \mu \mathrm{g}$ plasmid DNA each), transferred to a cuvette, and nucleofected using program DT-130 of the nucleofector device. Nucleofected cells were transferred to $500 \mu \mathrm{l}$ prewarmed medium and seeded in 24-well plates at a density of $1.25 \times 10^{5}$ cells per well. The cells were cultured overnight and treated with CSE in a range of concentrations for a further 24 hours in DMEM supplemented with $10 \%$ FBS. To assess RUNX2 activity using the luciferease reporter assay, the cell lysates were prepared with reporter Passive Lysis Buffer (Promega, USA), and luciferase activity was quantified using the Dual-Luciferase Reporter Assay System (Promega, USA). Luminescence was measured using an AutoLumat LB 953 instrument (Berthold Technologies, Finland).

\section{Preparation of Cell Lysates and Western Blot Analysis}

Cells were incubated for $30 \mathrm{~min}$ in NP-40 lysis buffer [ $20 \mathrm{mM}$ Tris pH 7.5 containing $140 \mathrm{mM} \mathrm{NaCl}, 1$ $\mathrm{mM}$ EDTA, 1\% (v/v) Nonidet P-40, $5 \mu \mathrm{M}$ 4-(2-aminoethyl) benzenesulfonyl fluoride hydrochloride (AEBSF), $1.5 \mathrm{nM}$ aprotinin, $10 \mathrm{nM}$ E-64, and $10 \mathrm{nM}$ leupeptin]. The cells were then sonicated and centrifuged at $12,000 \times \mathrm{g}$ for $10 \mathrm{~min}$ at $4^{\circ} \mathrm{C}$ to remove insoluble debris. Total proteins $(30 \mu \mathrm{g})$ were resolved in an SDS-polyacrylamide gel and transferred onto a nitrocellulose membrane using the semidry technique. The membranes were blotted with antibodies 
against FOXO1, phospho-FOXO1, AKT, and phospho-AKT (Cell Signaling Technology, USA), and the proteins were identified using the Pierce ECL detection system (Thermo Scientific, USA).

\section{Statistical Analysis}

All experiments were performed using triplicate cultures, and the results are expressed the mean \pm standard deviation (SD). Statistical analyses were conducted using GraphPad Prism software. Data were evaluated by one-way ANOVA with Tukey's multiple comparison test. Differences with a p-value $<0.05$ were considered statistically significant.

\section{Results}

CSE at Concentrations less than 0.5\% Does not Have a Significant Effect on Proliferation of

\section{Periosteum-derived cells}

Periosteum-derived cells in primary culture had a fibroblastic appearance. Proliferation of the cells was unchanged after culture in $0.5 \%$ CSE compared to that of control cells cultured in the absence of CSE. However, CSE significantly decreased proliferation in a concentration-dependent manner at concentrations of $1 \%$ and greater (Fig. 1). This result suggests that CSE at concentrations less than $0.5 \%$ does not have a significant Effect on Proliferation of Periosteum-derived cells and CSE may decrease the viability of periosteum-derived cells at concentrations greater than $0.5 \%$. Based on this finding, cells were treated with CSE at concentrations less than or equal to $0.5 \%$ in the remainder of experiments.

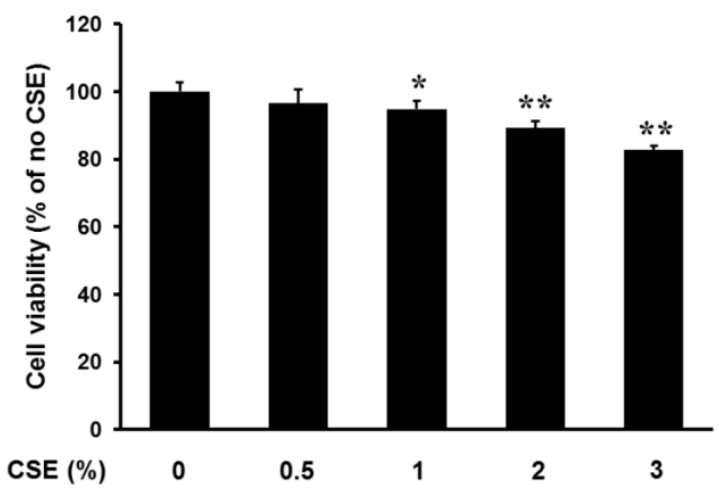

Figure 1. Effect of CSE on proliferation of periosteum-derived cells. Viability of cells incubated with the indicated concentrations of CSE is expressed as a percentage of the control viability. $* P<0.05$ and $* * P<0.01$, as compared to $0 \%$ CSE (control)
CSE Inhibits the Development of Osteoblastic Phenotypes in Periosteum-derived cells

After culturing cells for 1 week, histochemical detection of ALP in the periosteum-derived cells tended to decrease with increasing concentrations of CSE, however, after culturing cells for 2 weeks, the staining was visibly decreased only in cells treated with $0.5 \%$ CSE. ALP bioactivity showed a decrease in activity when cells were treated for 1 week with CSE concentrations of $0.05 \%$ and higher and when cells were treated for 2 weeks with CSE concentrations of $0.1 \%$ and higher. Although CSE at concentrations less than $0.1 \%$ did not significantly alter alizarin red-positive mineralization and calcium content in the periosteum-derived cells, $0.1 \%$ and $0.5 \%$ CSE concentrations clearly decreased both mineralization and calcium content in a concentration dependent manner (Fig. 2). These results suggest that CSE exerts inhibitory effects on osteoblastic differentiation of the periosteum-derived cells by decreasing ALP activity and mineralization.

\section{CSE Decreases Expression of ALP and OC mRNA in Periosteum-derived cells}

Baseline expression levels of ALP and OC mRNA were increased over 2 weeks in culture. Treatment with CSE tended to cause a decrease in ALP mRNA expression below control levels in the periosteum-derived cells after 3-day and 2-week treatments. At 3 days, $0.1 \%$ and $0.5 \%$ CSE concentrations significantly decreased ALP expression below the control level. ALP expression was also markedly decreased below control levels after treatment with $0.5 \%$ CSE for 3 days and for 1 and 2 weeks.

In addition, with the exception of $0.01 \%$ CSE, treatment with CSE caused significant concentration-dependent inhibition of ALP mRNA expression in the cells after 2 weeks of treatment. Although $0.1 \%$ CSE significantly, but transiently, increased OC expression at 3 days, treatment with CSE had no effect on OC expression beyond that of osteogenic medium. All tested concentrations of CSE significantly increased OC expression in the cells after 1 week of treatment; however, CSE decreased osteogenic differentiation and medium-induced OC expression at 3 weeks at all concentrations equal to or greater than $0.01 \%$ (Fig. 3). Similar to the effects of CSE on ALP activity and mineralization, these results suggest that CSE also exerts inhibitory effects on osteoblastogenesis of periosteum-derived cells by decreasing ALP and OC expression at the mRNA level. 
A
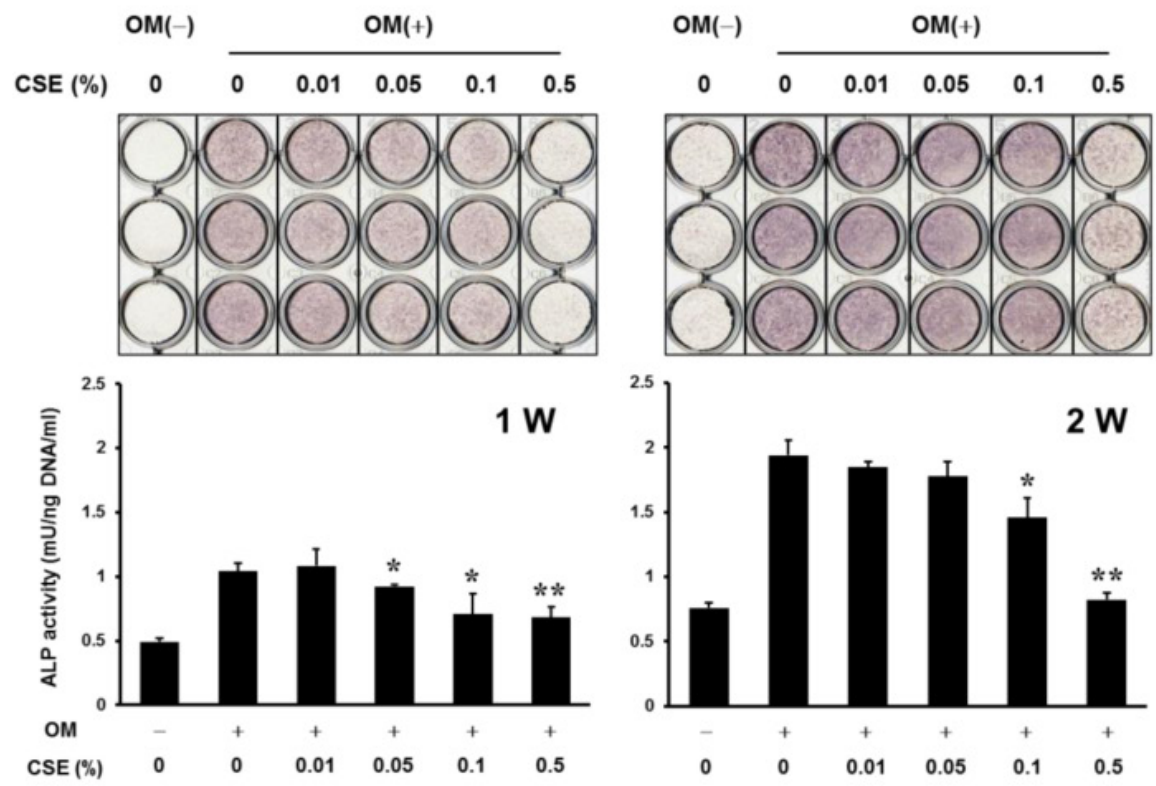

B
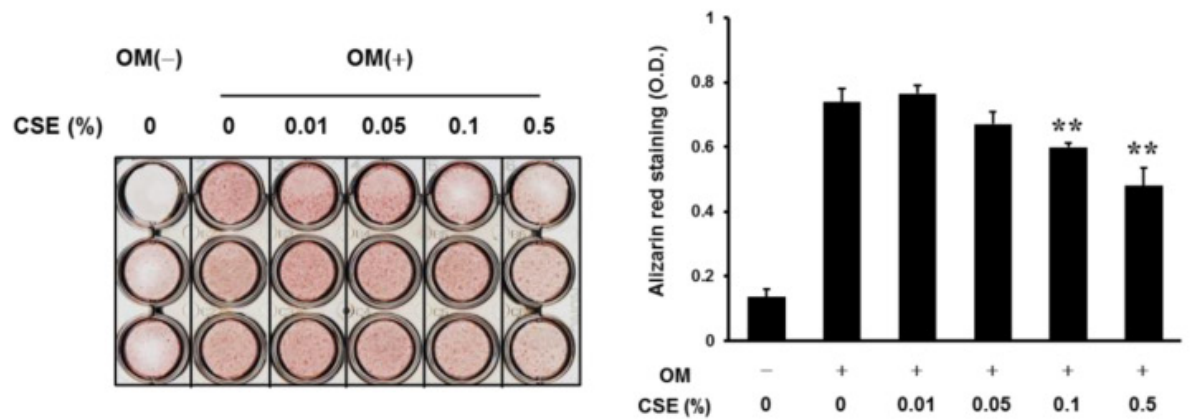

C

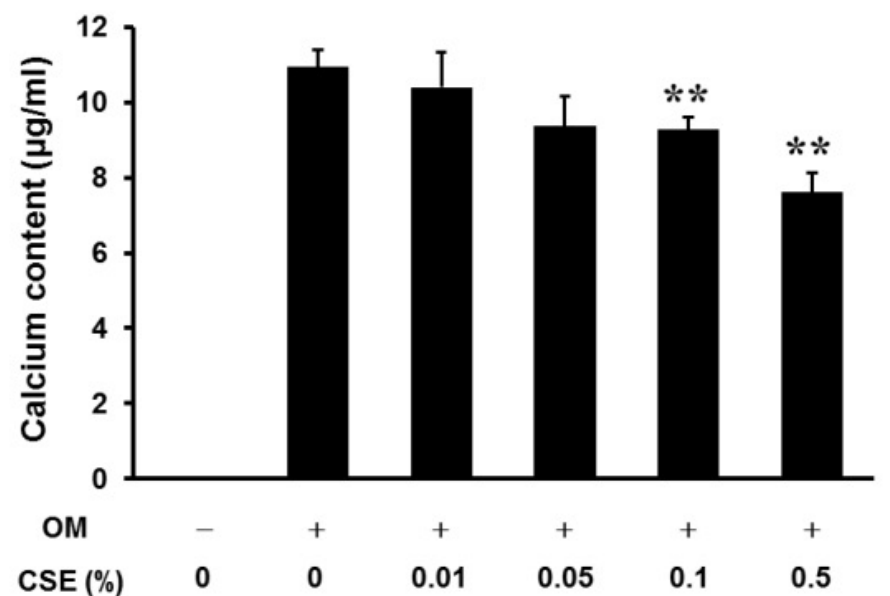

Figure 2. In vitro osteogenic phenotypes and mineralization of periosteum-derived cells treated with CSE. A: Histochemical staining of periosteum-derived cells cultured in osteogenic induction medium $(\mathrm{OM}(+))$ or control medium $(\mathrm{OM}(-))$ and treated with the indicated concentrations of CSE at 1 and 2 weeks $(\mathrm{W})$ of culture (upper) and ALP bioactivity (lower) B: Alizarin red staining of mineralized matrix in cells treated with the indicated concentrations of CSE and quantitation based on optical density (OD) C: calcium content of CSE-treated cells (c). $* P<0.05$ and $* * P<0.01$, as compared to $0 \%$ CSE in OM+. 
A

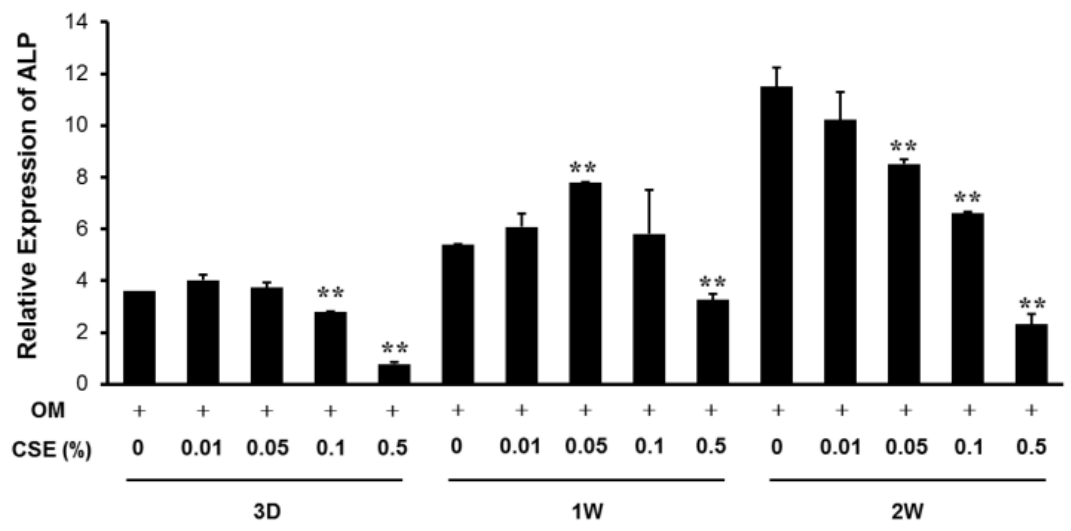

B

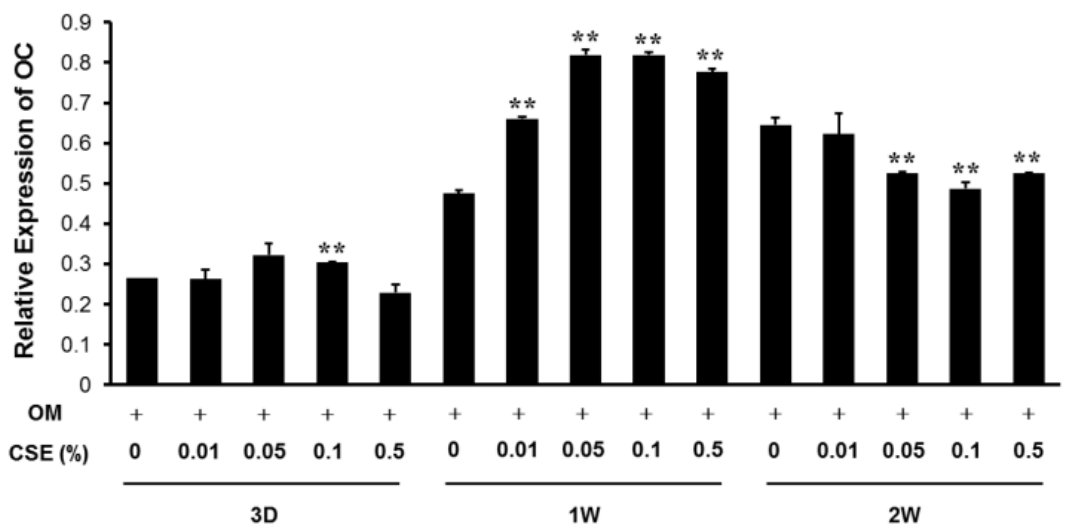

Figure 3. Quantitative RT-PCR analysis. Relative expression of ALP (A) and osteocalcin (B) mRNA in periosteum-derived cells cultured in osteogenic induction medium and treated with the indicated concentrations of CSE. ALP, alkaline phosphatase; OC, osteocalcin; OM, osteogenic induction medium; 3D, 3 days; 1W, 1 week; $2 \mathrm{~W}, 2$ weeks. $* * P<0.01$, as compared to $0 \%$ CSE in OM+.

\section{CSE Decreases RUNX2 Transcriptional Ac- tivity in the Periosteum-derived cells and Runx2 Affects ALP and OC Expression}

RUNX2 is a master regulator of osteoblast differentiation and bone development. The binding of nuclear RUNX2 to osteoblast-specific elements upregulates skeletal genes and, consequently, promotes development of the osteoblast phenotype $[13,20]$. RUNX2 transcriptional activity tended to decrease in a concentration-dependent manner when the periosteum-derived cells were treated with CSE and significantly decreased in cells treated with $0.1 \%$ and $0.5 \%$ CSE, which obviously affected ALP activity and matrix mineralization. Overexpression of RUNX2 increased expression of endogenous ALP and OC mRNA in periosteum-derived cells cultured in osteogenic induction medium. In addition, overexpression of RUNX2 enhanced OC expression in the cells cultured in control DMEM (Fig. 4). These results suggest that CSE decreases RUNX2 transcriptional activity in the periosteum-derived cells and RUNX2 affects ALP and OC expression. The inhibitory effects of CSE might be dependent of RUNX2 in the in vitro osteoblastic differentiation of cultured human periosteum-derived cells.

\section{CSE Treatment Decreases FOXO1 Phos- phorylation and Inhibits Transcriptional Ac- tivity of RUNX2 in Periosteum-derived cells}

AKT (also known as protein kinase B [PKB]) regulates metabolic homeostasis in part by modulating transcriptional activity of the FOXO proteins, including FOXO1, through phosphorylation [21]. Treatment of the periosteum-derived cells with CSE decreased phosphorylation of AKT and FOXO1. To examine the functional role of FOXO1 on RUNX2 activity in the periosteum-derived cells, transcriptional activity of RUNX2 was evaluated in cells transiently transfected with a p6xOSE2-Luc reporter and combinations of expression vectors encoding RUNX2, wild-type (FOXO1-WT), and constitutively active (FOXO1-A3) FOXO1. RUNX2 transactivation was increased in cells overexpressing RUNX2. However, 
this activity was abrogated in cells overexpressing FOXO1-A3 (Fig. 5). This result suggests that CSE treatment decreases FOXO1 phosphorylation and inhibits transcriptional activity of RUNX2 in periosteum-derived cells and FOXO1 regulates RUNX2 transcriptional activity in a FOXO1 phosphorylation-dependent manner.

\section{Discussion}

Cigarettes typically contain approximately 1.2-2 mg nicotine, depending on the brand and the presence or absence of a filter. Nicotine is the major ingredient of cigarette smoke, and smoking has been shown to be associated with negative effects on bone metabolism and skeletal remodeling [6]. However, including biphasic effects with stimulatory effects at low doses and negative effects at higher levels, the effects of nicotine on cultured osteoprogenitor cells remain controversial [22-24]. In a study using the MG-63 human osteoblast-like cell line, Rothem et al [25] demonstrated statistically significant changes in 842 genes in cells exposed to $100 \mu \mathrm{M}$ nicotine and examined low-dose nicotine-induced upregulated expression of OC, type I collagen, and ALP. Another study examined the dose-dependent positive effect of nicotine on the osteoblastic activity of rabbit bone marrow-derived osteoblast-like cells and suggested that nicotine may not be responsible for the impaired bone healing observed in smokers [26]. Previous studies by the same group also showed that nicotine delivered via a transdermal nicotine patch significantly enhanced posterior spinal fusion rates in rabbits [27].

A

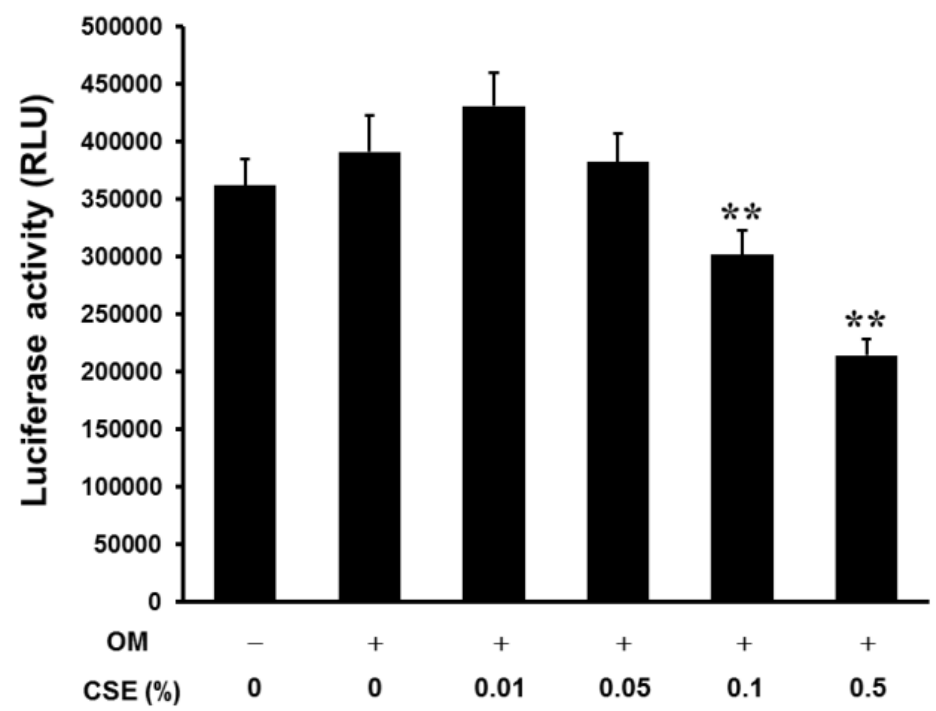

B
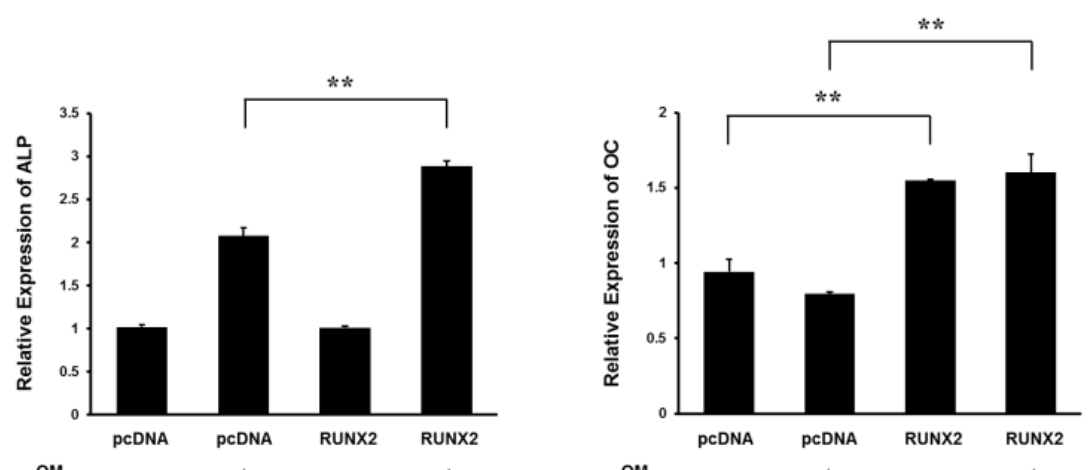

Figure 4. Activation of RUNX2 transcriptional activity by CSE in periosteum-derived cells. A: Luciferase activity showing RUNX2 transcriptional activity in cells cultured in osteogenic induction medium (OM+) or control medium (OM-) and treated with the indicated concentrations of CSE B: Relative expression of ALP and OC mRNA in cells cultured in osteogenic induction or control medium and transfected with control (PcDNA) or RUNX2 constructs (b). **P< < 0.01 , as compared to $0 \%$ CSE in OM+. 
A

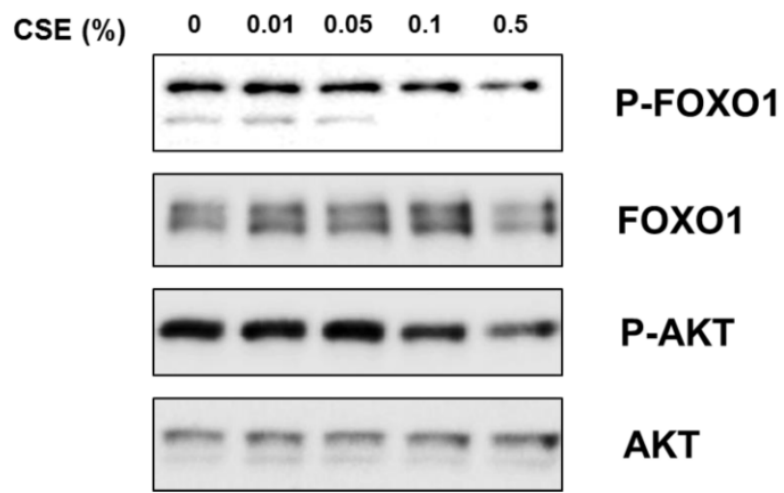

B

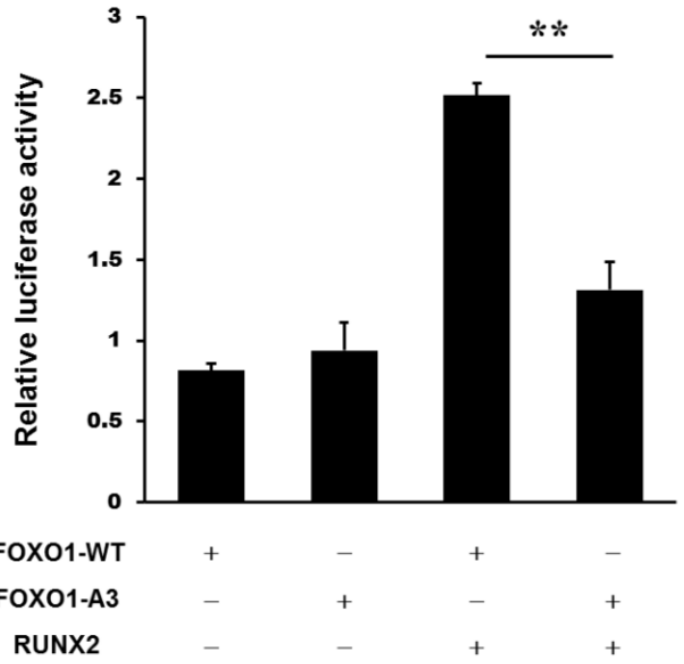

Figure 5. Activation of RUNX2 transcriptional activity by CSE in the periosteum-derived cells. A: Western analysis of expression of the indicated proteins in periosteum-derived cells treated with the indicated concentrations of CSE B: Luciferase activity showing RUNX2 transcriptional activity in cells co-nucleofected with wild-type FOXO1 and the AKT phosphorylation-resistant mutant FOXO1-A3 (b). FOXOI-WT, wild-type FOXO1; FOXO1-A3, constitutively active FOXO1. $* * P<0.01$

Although nicotine is a major component of the particulate phase of all cigarette smoke and is maintained in body tissues at a high level by habitual smoking, the effects of smoking exposure versus nicotine exposure on bone may differ. Skott et al [28] investigated the influence of nicotine and nicotine-free tobacco extract, alone and in combination, on mechanical strength of closed femoral fractures in a rat femur fracture model. When mechanically testing fracture healing, ultimate torque and torque at the yield point of the tobacco extract group were decreased by $20 \%$ and $26 \%$, respectively, compared with the nicotine group. Also, an $18 \%$ reduction in torque at the yield point was observed in the combination group compared with the nicotine group. However, no difference was found between the tobacco extract and combination groups. Another study reported that nicotine can act as a direct stimulant of bone cell metabolic activity and that smoke condensate (containing equivalent levels of nicotine) elicits an inhibitory effect in murine MC3T3-E1 osteoblast-like cells [29]. These results suggest that smoking, rather than just exposure to nicotine, may be the principal factor.

In the present study, the viability of periosteum-derived cells was not changed upon exposure to CSE at concentrations at or below $0.5 \%$. We focused on the effects of CSE on osteoblastic differentiation, not viability, of cultured human periosteum-derived cells. Furthermore, few studies have been conducted to investigate the effects of CSE on osteoblastic differentiation of cultured human periosteum-derived cells. Therefore, we examined the effects of CSE at concentrations ranging from $0.01 \%$ to $0.5 \%$ on osteoblastic differentiation. CSE tends to decrease ALP activity and mineralization in a concentration-dependent manner and, at concentrations of $0.1 \%$ and $0.5 \%$, significantly decreased ALP activity, alizarin red S-positive mineralization, and the calcium content of periosteum-derived cells. Quantitative RT-PCR clearly showed that, with the exception of a CSE concentration at $0.01 \%$, treatment with CSE resulted in concentration-dependent inhibition of ALP expression after 2 weeks of treatment. Furthermore, $0.1 \%$ CSE and $0.5 \%$ CSE already significantly decreased ALP expression below control levels in the periosteum-derived cells after 3 days of treatment. After 1 week in osteogenic differentiation medium, CSE increased expression of OC mRNA in the periosteum-derived cells; however, CSE (with the exception of $0.01 \%$ ) significantly decreased osteogenic induction medium-induced OC expression at 2 weeks. Considering that ALP is an early marker of osteoblast differentiation, whereas OC secretion is associated with the late phase of osteoblast differentiation, the RT-PCR results suggest that CSE may have inhibitory effects on osteoblastic differentiation of the cultured human periosteum-derived cells by affecting ALP (at earlier time points) and mineralization (at later time points). Further studies will be needed to assess the temporal pattern of CSE effects on osteoblastic differentiation of osteoprogenitors.

RUNX2 is frequently described as the master regulator of osteoblastogenesis. Through several pathways, the binding of nuclear RUNX2 to osteoblast-specific elements upregulates skeletal genes and, consequently, promotes the development of the osteoblast phenotype. Many studies have reported that the essential role of functional RUNX2 expression is in embryonic bone formation, as well as regulation of bone matrix deposition by differentiated osteoblasts throughout life [14,20,30-32]. In the present study, ALP and OC expression decreased in the perioste- 
um-derived cells that were transiently transfected with a p6xOSE2-Luc reporter together with a RUNX2 expression vector in osteogenic induction medium.

The FOXO subfamily of transcription factors, which includes FOXO1, FOXO3, FOXO4, and FOXO6, regulates diverse cellular processes, including stress response, cell cycle arrest, DNA damage repair, and differentiation. The activity of FOXO1, as a member of this family, is regulated by several exogenous stimuli, such as growth factors and oxidative stress. These stimuli activate or inactivate FOXO1 by posttranscriptional modifications and subcellular localization. The phosphorylation of FOXO1 leads to its cytoplasmic retention and the inhibition of its transcriptional activity. On the other hand, dephosphorylation localizes FOXO1 to the nucleus, where it binds to the forkhead response element within the promoters of multiple target genes, resulting in transcriptional regulation $[16,21,33]$. Although, of the FOXO proteins, FOXO1 regulates the most diverse array of known FOXO biological activities (including organ growth, insulin action, and tumorigenesis), its effects on osteoblastic differentiation of osteoprogenitor cells have not yet been fully investigated. In this study, we identified FOXO1 as a negative regulator of the bone transcription factor Runx2 in periosteum-derived osteoblasts. Decreased phosphorylation of AKT and FOXO1 was observed in the periosteum-derived cells treated with CSE. The AKT phosphorylation-resistant mutant FOXO1-A3 had a clearly inhibitory effect on the transcriptional activity of RUNX2 in the periosteum-derived cells.

This study examined the only osteoblastic differentiation of cultured human periosteal-derived cells treated with CSE under conditions that maintain cell viability. In addition, the role of FOXO1 was observed during osteoblastic differentiation of the periosteum-derived cells treated with CSE. In conclusion, although further studies will be needed to clarify the mechanisms of FOXO1-regulated osteogenesis of periosteum-derived cells, our results suggest that FOXO1 is involved in the mechanism by which CSE exposure leads to inhibition of osteoblastic differentiation of cultured human periosteum-derived cells.

\section{Acknowledgement}

This study was supported by a grant of the Korean Health Technology R\&D Project, Ministry of Health \& Welfare, Republic of Korea (HI13C1596).

\section{Competing Interests}

The authors have declared that no competing interest exists.

\section{References}

1. Bai XC, Lu D, Bai J, Zheng H, Ke ZY, Li XM, Luo SQ. Oxidative stress inhibits osteoblastic differentiation of bone cells by ERK and NF-kappaB. Biochem Biophys Res Commun 2004;314(1):197-207.

2. Rothem DE, Rothem L, Soudry M, Dahan A, Eliakim R. Nicotine modulates bone metabolism-associated gene expression in osteoblast cells. J Bone Miner Metab 2009;27(5):555-561.

3. Chassanidis CG, Malizos KN, Varitimidis S, Samara S, Koromila T, Kollia P, Dailiana Z. Smoking affects mRNA expression of bone morphogenetic proteins in human periosteum. J Bone Joint Surg Br 2012;94(10):1427-1432.

4. Holzer N, Braun KF, Ehnert S, Egaña JT, Schenck TL, Buchholz A, Schyschka L, Neumaier M, Benzing S, Stöckle U, Freude T, Nussler AK. Green tea protects human osteoblasts from cigarette smoke-induced injury: possible clinical implication. Langenbecks Arch Surg 2012;397(3):467-474.

5. Kung $\mathrm{MH}$, Yukata K, O'Keefe RJ, Zuscik M J. Aryl hydrocarbon receptor-mediated impairment of chondrogenesis and fracture healing by cigarette smoke and benzo(a)pyrene. J Cell Physiol 2012;227(3):1062-1070.

6. Kallala R, Barrow J, Graham SM, Kanakaris N, Giannoudis PV. The in vitro and in vivo effects of nicotine on bone, bone cells and fracture repair. Expert Opin Drug Saf 2013;12(2):209-233.

7. Campos ML, Corrêa MG, Júnior FH, Casati MZ, Sallum EA, Sallum AW. Cigarette smoke inhalation increases the alveolar bone loss caused by primary occlusal trauma in a rat model. J Periodontal Res 2014;49(2):179-185.

8. Devlin H, Sloan P. Early bone healing events in the human extraction socket. Int J Oral Maxillofac Surg 2002;31(6):641-645.

9. Halabí D, Escobar J, Muñoz C, Uribe S. Logistic regression analysis of risk factors for the development of alveolar osteitis. J Oral Maxillofac Surg 2012;70(5):1040-1044.

10. Park BW, Hah YS, Kim DR, Kim JR, Byun JH. Osteogenic phenotypes and mineralization of cultured human periosteal-derived cells. Arch Oral Biol 2007;52(10):983-989.

11. Lee JH, Hah YS, Cho HY, Kim JH, Oh SH, Park BW, Kang YH, Choi MJ, Shin JK, Rho GJ, Jeon RH, Lee HC, Kim GC, Kim UK, Kim JR, Lee CI, Byun JH. Human umbilical cord blood-derived CD34-positive endothelial progenitor cells stimulate osteoblastic differentiation of cultured human periosteal-derived osteoblasts. Tissue Eng Part A 2014;20(5-6):940-953.

12. Ducy P, Zhang R, Geoffroy V, Ridall AL, Karsenty G. Osf2/Cbfa1: a transcriptional activator of osteoblast differentiation. Cell 1997;89(5):747-754.

13. Ziros PG, Gil AP, Georgakopoulos T, Habeos I, Kletsas D, Basdra EK, Papavassiliou AG. The bone-specific transcriptional regulator Cbfa1 is a target of mechanical signals in osteoblastic cells. J Biol Chem 2002;277(26):23934-23941.

14. Lin GL, Hankenson KD. Integration of BMP, Wnt, and notch signaling pathways in osteoblast differentiation. J Cell Biochem 2011;112(12):3491-501.

15. Nakae J, Kitamura T, Kitamura Y, Biggs WH 3rd, Arden KC, Accili D. The forkhead transcription factor Foxo1 regulates adipocyte differentiation. Dev Cell 2003;4(1):119-129.

16. van der Vos KE, Coffer PJ. FOXO-binding partners: it takes two to tango. Oncogene 2008;27(16):2289-2299.

17. Kousteni S. FoxO1: a molecule for all seasons. J Bone Miner Res 2011;26(5):912-917

18. Zhang H, Pan Y, Zheng L, Choe C, Lindgren B, Jensen ED, Westendorf JJ, Cheng L, Huang H. FOXO1 inhibits Runx2 transcriptional activity and prostate cancer cell migration and invasion. Cancer Res 2011;71(9):3257-3267.

19. Hah YS, Kang HG, Cho HY, Shin SH, Kim UK, Park BW, Lee SI, Rho GJ, Kim JR, Byun JH. JNK signaling plays an important role in the effects of TNF- $\alpha$ and IL-1 $\beta$ on in vitro osteoblastic differentiation of cultured human periosteal-derived cells. Mol Biol Rep 2013;40(8):4869-4881.

20. Li Y, Ge C, Long JP, Begun DL, Rodriguez JA, Goldstein SA, Franceschi RT. Biomechanical stimulation of osteoblast gene expression requires phosphorylation of the RUNX2 transcription factor. J Bone Miner Res 2012;27(6):1263-1274

21. Matsuzaki H, Daitoku H, Hatta M, Tanaka K, Fukamizu A. Insulin-induced phosphorylation of FKHR (Foxo1) targets to proteasomal degradation. Proc Natl Acad Sci U S A 2003;100(20):11285-11290.

22. Walker LM, Preston MR, Magnay JL, Thomas PB, El Haj AJ. Nicotinic regulation of c-fos and osteopontin expression in human-derived osteoblast-like cells and human trabecular bone organ culture. Bone 2001;28(6):603-608.

23. Gotfredsen $\mathrm{K}$, Lindh $\mathrm{CH}$, Berglundh $\mathrm{T}$. Does longstanding nicotine exposure impair bone healing and osseointegration? An experimental study in rabbits. J Biomed Mater Res B Appl Biomater 2009;91(2):918-923.

24. Kim BS, Kim SJ, Kim HJ, Lee SJ, Park YJ, Lee J, You HK. Effects of nicotine on proliferation and osteoblast differentiation in human alveolar bone marrow-derived mesenchymal stem cells. Life Sci 2012;90(3-4):109-115.

25. Rothem DE, Rothem L, Dahan A, Eliakim R, Soudry M. Nicotinic modulation of gene expression in osteoblast cells, MG-63. Bone 2011;48(4):903-909.

26. Daffner SD, Waugh S, Norman TL, Mukherjee N, France JC. Nicotine Increases Osteoblast Activity of Induced Bone Marrow Stromal Cells in a Dose-Dependent Manner: An in vitro Cell Culture Experiment. Global Spine J 2012;2(3):153-158.

27. France JC, Norman TL, Buchanan MM, Scheel M, Veale $M$, Ackerman ES, Clovis NB, Kish VL, Simon B. Direct current stimulation for spine fusion in a nicotine exposure model. Spine J 2006;6(1):7-13

28. Skott M, Andreassen TT, Ulrich-Vinther M, Chen X, Keyler DE, LeSage MG, Pentel PR, Bechtold JE, Soballe K. Tobacco extract but not nicotine impairs the 
mechanical strength of fracture healing in rats. J Orthop Res 2006;24(7):1472-1479.

29. Gullihorn L, Karpman R, Lippiello L. Differential effects of nicotine and smoke condensate on bone cell metabolic activity. J Orthop Trauma 2005;19(1):17-22.

30. Byers BA, Pavlath GK, Murphy TJ, Karsenty G, García AJ. Cell-type-dependent up-regulation of in vitro mineralization after overexpression of the osteoblast-specific transcription factor Runx2/Cbfal. J Bone Miner Res 2002;17(11):1931-1944.

31. Takahashi T. Overexpression of Runx2 and MKP-1 stimulates transdifferentiation of 3T3-L1 preadipocytes into bone-forming osteoblasts in vitro. Calcif Tissue Int 2011;88(4):336-347.

32. Sheng H, Rui XF, Sheng CJ, Li WJ, Cheng XY, Jhummon NP, Yu YC, Qu S, Zhang G, Qin L. A novel semisynthetic molecule icaritin stimulates osteogenic differentiation and inhibits adipogenesis of mesenchymal stem cells. Int J Med Sci. 2013;10(6):782-789.

33. Shen M, Lin F, Zhang J, Tang Y, Chen WK, Liu H. Involvement of the up-regulated FoxO1 expression in follicular granulosa cell apoptosis induced by oxidative stress. J Biol Chem 2012;287(31):25727-25740. 